\title{
Estado do conhecimento acerca de especificações técnicas e normativas para agregados reciclados de RCD
}

\author{
State-of-art review of current standards and \\ specifications concerning recycled aggregates from CDW
}

\section{Elaine Pinto Varela Alberte Julia Barretto Handro}

\section{Resumo}

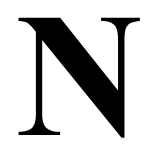

o Brasil existem normas específicas que estabelecem diretrizes para uso de agregados reciclados em pavimentação e em concreto sem função estrutural. Contudo, pelo fato de a reciclagem de resíduos de construção e demolição (RCD) ainda ser considerada uma atividade recente no país quando comparada a países mais desenvolvidos, torna-se compreensível haver lacunas a respeito da normatização desses materiais, bem como resistência por parte da indústria da construção em utilizá-los. Este estudo realizou um levantamento estruturado sobre produção técnica e normativa existente nos cenários nacional e internacional para o uso de agregados reciclados. Foram consideradas especificações técnicas, normativas e de controle de qualidade de 12 países, incluindo o Brasil. Uma análise sistemática das normas permitiu a apreciação da produção técnica e normativa internacional suplementada com uma breve comparação com a última revisão nacional sobre o tema. Isso possibilitou o delineamento de sugestões para diretrizes técnicas e normativas para o uso desses materiais no país. Espera-se que os resultados deste trabalho apoiem o setor na evolução de especificações técnicas relacionadas e produzam contribuições exitosas em caráter prático para consolidar a reciclagem de RCD do país.

Palavras-chave: Resíduos de construção e demolição. Agregado reciclado. Especificações técnicas. Especificações normativas.

\begin{abstract}
Brazil has specific standards that guide the use of recycled aggregates in pavement construction and nonstructural concrete. However, due to the fact that the recycling of construction and demolition waste $(C D W)$ is still a recent activity in the in Brazil, when compared to other countries, it is understandable that there is a gap regarding the standardization of these materials, as well as some resistance by the construction industry to using them. This study conducts a systematic analysis of the literature on technical and normative specifications on the use of recycled aggregates at a national and international level. In this analysis, the technical, regulatory and quality control standards and guidelines for the use of recycled aggregates from 12 countries, including Brazil were examined. A systematic analysis of the standards allowed an appraisal of the international technical and normative production examined, supplemented by a brief comparison with the latest national review on the subject. This enabled the authors to develop a proposal for technical and normative guidelines for the use of recycled construction and demolition materials in Brazil. It is expected that the results of this study will support the sector in the further development of technical specifications and standards, producing practical contributions for the consolidation of the CDW recycling in the country.
\end{abstract}

Julia Barretto Handro Universidade Federal da Bahia Salvador BA - Brasil

Recebido em 01/07/20 Aceito em 04/01/21
Keywords: Construction and demolition waste. Recycled aggregate. Technical specifications. Standards. 


\section{Introdução}

O setor da construção civil se destaca pela significativa quantidade de resíduos de construção e demolição (RCD) gerada - 45,1 milhões de toneladas/ano somente no Brasil (ASSOCIAÇÃO..., 2017). Uma das alternativas para a gestão desses resíduos é a reciclagem, transformando o resíduo em um agregado potencialmente útil, como material de construção. As aplicações desse agregado são diversas, desde seu uso como material granular para pavimentos, drenagem e terraplenagem, até como substituição total ou parcial de agregados naturais para produção de concreto, argamassa e elementos pré-moldados.

Muitos países, como Japão, Alemanha e Holanda, já possuem especificações técnicas consolidadas que regulam o uso desses agregados reciclados como material de construção. Outros caminham para a incorporação desses materiais em regulamentações voltadas ao setor. As aplicações, no entanto, variam segundo cada país, tendo em vista as particularidades da região relacionadas com a oferta de matéria-prima, geração de RCD, disponibilidade de locais para deposição, restrições normativas, entre outros fatores.

No Brasil, a falta de um mercado de reciclagem de RCD consolidado é atribuída à dificuldade da indústria da construção civil em conhecer o potencial técnico do agregado reciclado (AR).

O presente artigo apresenta um levantamento estruturado sobre a produção técnica e normativa existente nos cenários nacional e internacional sobre o uso de AR com material de construção. Os resultados apresentados pretendem contribuir para a obtenção de um panorama mais amplo e comparativo do que existe atualmente acerca o tema no Brasil e no mundo, que permita identificar a evolução das publicações normativas e as lacunas existentes nesse campo no país.

\section{Agregados reciclados de RCD: cenário mundial sobre especificações técnicas e normativas}

Pesquisas direcionadas ao estudo das propriedades do concreto produzido com resíduos de construção tiveram início em 1928, na Europa (LEVY, 2002). No entanto, foi no período pós-Segunda Guerra Mundial que o continente europeu, ao necessitar encontrar uma solução para todo o resíduo gerado por consequência da guerra, se tornou precursor da reciclagem de RCD.

Países como Bélgica, Alemanha, Inglaterra e Holanda tiveram contribuições relevantes para a reciclagem de RCD por volta da década de 1980. O Instituto de Pesquisa de Construção da Bélgica (BBRI) publicou em 1979 pesquisas sobre concretos reciclados que possibilitaram a instalação da primeira usina de reciclagem do país, em 1986 (VYNCKE; VRIJDERS, 2010). A Alemanha, por sua vez, criou nesse mesmo período a Associação Federal de Qualidade para Materiais de Construção Reciclados em Berlim com a principal função de unir as maiores empresas de reciclagem na Alemanha (TAM; SOOMRO; EVANGELISTA, 2018).

$\mathrm{Na}$ Holanda, os problemas causados pelo acúmulo de resíduo pós-guerra coincidiram com o período de dificuldade de extração de material natural, o que estimulou o uso do RCD (VÁZQUEZ, 2016). Em 1983, a Comissão Holandesa de Pesquisa da Associação do Concreto (CUR) propôs uma norma para o uso de AR em concreto. Dois anos mais tarde, a norma britânica BS 6543 abrangeu o uso de AR em terraplenagem, bases e sub-bases de pavimentos, concreto e blocos (HANSEN, 1986).

Devido à pequena extensão terrestre e aos recursos relativamente escassos, o governo japonês também foi um dos primeiros a incentivar a reciclagem e reutilização de RCD. Em 1977, a Associação de Empreiteiros do Japão (BSCJ) formulou sua primeira especificação (XIAO, 2018). Na Austrália, a reciclagem de RCD é notada desde a década de 1960, em pavimentos asfálticos. Desde então, tem havido um crescimento do setor, com AR comercialmente disponíveis em Sydney e Melbourne (RATCLIFFE, 2016).

Os Estados Unidos também foram um dos países pioneiros nesse tema. Segundo Affonso (2005), após 1982, normas americanas para pavimentos e concretos passam a apresentar condições para a reciclagem de RCD. Em meados da década de 80, AR de concreto foram usados na construção de uma estrada pelo Departamento de Transportes do Estado do Kansas (XIAO, 2018).

No Brasil, a gestão de RCD teve início cerca de seis décadas após a Europa (MELO, 2011). Em 1991, foi implantada em São Paulo a primeira usina de reciclagem de RCD da América Latina. Contudo, suas atividades foram encerradas em 2002, sem o alcance máximo de capacidade de produção (NUNES, 2004). Em 2002, foi publicada a Resolução CONAMA n 307 , que estabeleceu condições e responsabilidades para 
a gestão de RCD (CONSELHO..., 2002). E, em 2003, a Prefeitura de São Paulo publicou especificação de serviço sobre uso de AR em pavimentação (PREFEITURA..., 2003).

Em decorrência dessas diretrizes, a ABNT publicou em 2004 um conjunto de normas relacionadas à gestão dos RCD, em que dispõe as condições necessárias para seu adequado manejo, beneficiamento e uso, uma vez reciclado (CUNHA, 2007). A partir de 2006, a Prefeitura de São Paulo tornou obrigatório o uso de AR em obras de pavimentação do município por meio do Decreto n ${ }^{\circ} 48.075$ (PREFEITURA..., 2006).

Na Figura 1 estão sintetizados em uma linha do tempo os principais acontecimentos que marcaram a trajetória da reciclagem de RCD no mundo.

Gonçalvez e Brito (2010) desenvolveram uma análise sobre normas e especificações de nove países referentes ao uso de concreto produzido com AR. Os autores analisam comparativamente os parâmetros de densidade, absorção à água e porcentagem de contaminantes, bem como porcentagem de AR, resistências máximas para o concreto e riscos do ambiente de utilização do concreto. Como resultado, constataram que a maior parte das especificações classifica os AR em termos de sua composição em concreto e cerâmica, sendo tal classificação variável por documento.

McNeil e Kang (2013), por outra parte, estudaram as propriedades dos AR de concreto e seus efeitos na produção de concreto, e identificaram que a densidade, a porosidade e a absorção de água dos AR são mais afetadas pela argamassa residual aderida aos grãos. Os autores também detectaram que as partículas de AR de concreto têm forma mais arredondada e maiores índices de desgaste à abrasão Los Angeles quando comparadas às partículas convencionais, devido à fraqueza das ligações criadas pela camada de argamassa residual. Além disso, a presença de AR no concreto, apesar de diminuir sua resistência à compressão, produz resistência à tensão equivalente ou superior. O módulo de ruptura do concreto, por sua vez, tende a ser menor que o do concreto convencional devido ao enfraquecimento da zona de transição da argamassa residual.

Finalmente, Tam, Soomro e Evangelista (2018) realizaram uma revisão sistemática da literatura entre 2000 e 2017 sobre uso do AR em concreto. Os autores realizaram comparações entre especificações e normas, e dados sobre geração e reciclagem de RCD, de diferentes países. Uma importante variação no nível de reciclagem e recuperação desses países foi observada, a exemplo do Brasil, Espanha, Japão e Holanda, que apresentaram os valores de $6 \%, 14 \%, 81 \%$ e $98 \%$, respectivamente. Tal variação é atribuída no estudo às características particulares de cada país, como oferta de materiais de construção e RCD, disponibilidade de locais para deposição e restrições das normas, entre outros fatores.

A Tabela 1 apresenta as especificações técnicas e normativas para AR oriundos de RCD identificadas neste estudo.

Figura 1 - Linha do tempo - reciclagem de RCD no mundo

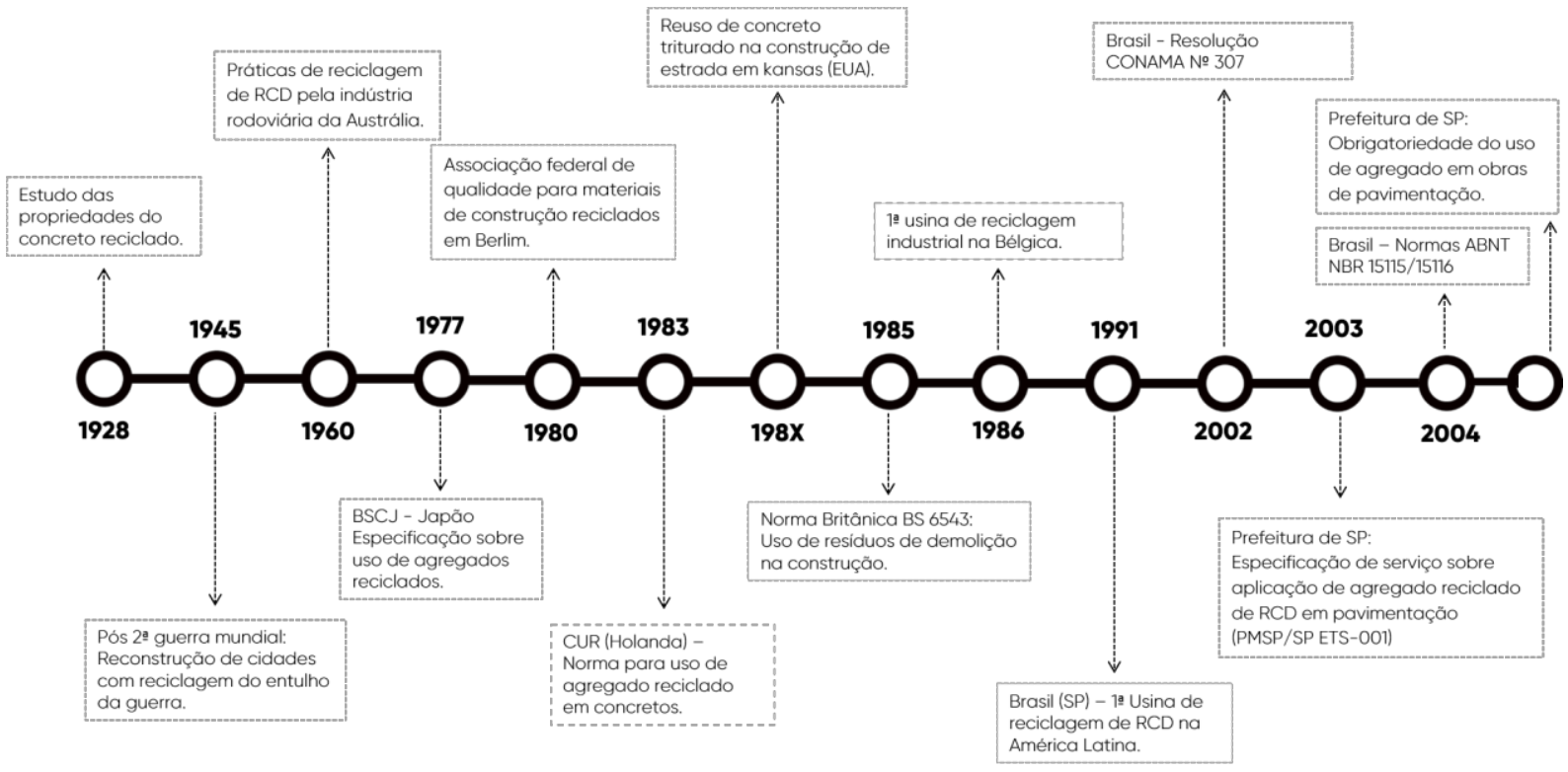

Estado do conhecimento acerca de especificações técnicas e normativas para agregados reciclados de RCD 
Tabela 1 - Especificações técnicas e normativas sobre AR identificadas

\begin{tabular}{|c|c|c|c|c|c|c|c|}
\hline \multirow[b]{2}{*}{ País } & \multirow[b]{2}{*}{ Norma } & \multirow[b]{2}{*}{ Ano } & \multicolumn{5}{|c|}{ Aplicação do AR } \\
\hline & & & $\begin{array}{c}\text { Pavi- } \\
\text { mentos }\end{array}$ & $\begin{array}{l}\text { Con- } \\
\text { creto }\end{array}$ & $\begin{array}{l}\text { Arga- } \\
\text { massas }\end{array}$ & $\begin{array}{c}\text { Terraple- } \\
\text { nagem }\end{array}$ & Outros \\
\hline \multirow{2}{*}{ Brasil } & NBR 15115 (ABNT, 2004a) & 2004 & $\mathrm{X}$ & & & & \\
\hline & NBR 15116 (ABNT, 2004b) & 2004 & $\mathrm{X}$ & $\mathrm{X}$ & & & \\
\hline \multirow{3}{*}{ Alemanha } & $\begin{array}{l}\text { DIN 4226-100 } \\
\text { (DEUTSCHES..., 2002) }\end{array}$ & 2002 & & $\mathrm{X}$ & $\mathrm{X}$ & & \\
\hline & $\begin{array}{l}\text { DAfStb (GONÇALVES; } \\
\text { BRITO, 2010) }\end{array}$ & 2010 & & $\mathrm{X}$ & & & \\
\hline & $\begin{array}{l}\text { TLGESTEIN-STB (ROAD..., } \\
\text { 2004) }\end{array}$ & 2004 & $\mathrm{X}$ & & & & \\
\hline Áustria & $\begin{array}{l}\text { OBRV; OGRB } \\
\text { (AUSTRIAN..., 2004) }\end{array}$ & 2004 & $\mathrm{X}$ & & & & $\mathrm{X}$ \\
\hline \multirow[t]{2}{*}{ Austrália } & $\begin{array}{l}\text { CSIRO HB155 } \\
\text { (COMMONWEALTH..., } \\
\text { 2002) }\end{array}$ & 2002 & $\mathrm{X}$ & $\mathrm{X}$ & & & \\
\hline & $\begin{array}{l}\text { DPTI (DEPARTMENT..., } \\
\text { 2001) }\end{array}$ & 2001 & $\mathrm{X}$ & & & $\mathrm{X}$ & \\
\hline \multirow{2}{*}{ Bélgica } & $\begin{array}{l}\text { PTV } 406 \text { (ORGANISME..., } \\
\text { 2016) }\end{array}$ & 2016 & $\mathrm{X}$ & & $\mathrm{X}$ & $\mathrm{X}$ & \\
\hline & $\begin{array}{l}\text { NBN B15-001 (BELGIUM..., } \\
\text { 2006) }\end{array}$ & 2006 & & $\mathrm{X}$ & & & \\
\hline \multirow{4}{*}{ Espanha } & $\begin{array}{l}\text { EHE-08 (MINISTERIO..., } \\
\text { 2008) }\end{array}$ & 2008 & & $\mathrm{X}$ & & & \\
\hline & $\begin{array}{l}\text { IHOBE/País Basco } \\
\text { (SOCIEDAD ..., 2011) }\end{array}$ & 2011 & $\mathrm{X}$ & $\mathrm{X}$ & $X$ & $\mathrm{X}$ & \\
\hline & GEAR (GRÊMIO..., 2012) & 2012 & $X$ & $\mathrm{X}$ & & $\mathrm{X}$ & $\mathrm{X}$ \\
\hline & $\begin{array}{l}\text { AOPJA/Andaluzia } \\
\text { (AGENCIA..., 2015) }\end{array}$ & 2015 & $\mathrm{X}$ & $\mathrm{X}$ & & & \\
\hline \multirow{3}{*}{$\begin{array}{l}\text { Estados } \\
\text { Unidos }\end{array}$} & MDOT (MICHIGAN..., 2012) & 2012 & $\mathrm{X}$ & $\mathrm{X}$ & & & \\
\hline & TxDOT (TEXAS..., 2014) & 2014 & $\mathrm{X}$ & & & & \\
\hline & FDOT (FLORIDA..., 2017) & 2017 & & $\mathrm{X}$ & & & \\
\hline \multirow{3}{*}{ Holanda } & $\begin{array}{l}\text { CUR (CUR AANBEVELING, } \\
\text { 1984) }\end{array}$ & 1984 & & $\mathrm{X}$ & & & \\
\hline & NEN 5905 (ROYAL..., 2005) & 2005 & & $\mathrm{X}$ & & & \\
\hline & $\begin{array}{l}\text { RAW (HENDRIKS; } \\
\text { JANSSEN; VÁZQUEZ..., } \\
\text { 2005) }\end{array}$ & 2005 & $\mathrm{X}$ & & & $\mathrm{X}$ & \\
\hline $\begin{array}{l}\text { Hong } \\
\text { Kong }\end{array}$ & $\begin{array}{l}\text { WBTC N }^{\circ} 12 \\
(\text { DEVELOPMENT } \\
\text { BUREAU..., 2002) }\end{array}$ & 2002 & $\mathrm{X}$ & $\mathrm{X}$ & & & \\
\hline \multirow{2}{*}{ Inglaterra } & $\begin{array}{l}\text { UKBS 8500-2 (BRITISH..., } \\
2006)\end{array}$ & 2006 & & $\mathrm{X}$ & & & \\
\hline & $\begin{array}{l}\text { BRE DIGEST } 433 \\
\text { (BUILDING..., 1998) }\end{array}$ & 1998 & & $\mathrm{X}$ & & & \\
\hline Japão & $\begin{array}{l}\text { JIS A } 5021 \text { / JIS A } 5022 \text { / JIS } \\
\text { A 5023 (JAPANESE..., 2005, } \\
2007,2006)\end{array}$ & $\begin{array}{l}2005 \\
2007 \\
2006\end{array}$ & & $\mathrm{X}$ & & & \\
\hline \multirow[b]{2}{*}{ Suíça } & $\begin{array}{l}\text { OT } 70085 \\
\text { (CONFÉDÉRATION..., 2006) }\end{array}$ & 2006 & & $\mathrm{X}$ & & & \\
\hline & $\begin{array}{l}\text { SN } 670 \text { 142/143/144 } \\
\text { (SWISS..., 1998a, 1998c, } \\
\text { 1998d) }\end{array}$ & 1998 & $\mathrm{X}$ & & & $\mathrm{X}$ & \\
\hline $\begin{array}{l}\text { França } \\
(*)\end{array}$ & TC 121-DRG (RILEM, 1994) & 1994 & & $\mathrm{X}$ & & & \\
\hline
\end{tabular}

Nota: *âmbito internacional. 


\section{Método}

O presente estudo compreende uma pesquisa do tipo estado do conhecimento, na qual se realizaram o mapeamento e a análise estruturada de publicações acerca de especificações técnicas, normativas e de controle de qualidade para uso de AR como material de construção.

Para tal, foram pesquisadas essencialmente normas, especificações técnicas, diretrizes, manuais, guias, artigos, dissertações, teses e livros que abordassem e discutissem o tema. Com essa documentação, foram identificadas e analisadas especificações e normativas existentes em 11 países além do Brasil (Alemanha, Holanda, Bélgica, Espanha, Suíça, Áustria, Inglaterra, Austrália, Hong Kong, Japão e EUA), bem como uma publicação de abrangência internacional (RILEM, 1994) (Tabela 1).

O levantamento das informações por norma/especificação técnica foi realizado de forma sistemática e comparativa mediante tabulação de dados. Os dados coletados foram definidos a partir da revisão bibliográfica e foram tratados e analisados dentro de três âmbitos de análise:

(a) composição dos agregados: identificação das classes de agregados determinadas, assim como os critérios de composição, conteúdo de impurezas aceito e presença de matéria orgânica. Para apoio à análise comparativa, adotou-se classificação unificada em que são considerados agregados reciclados de concreto (ARC) aqueles cuja composição em concreto prevaleça em relação à composição de cerâmica. De forma análoga, agregados reciclados cerâmicos (ARCE) serão aqueles que possuem maior composição em materiais cerâmicos; e agregados reciclados mistos (ARM), com ambos os materiais em porcentagens significativas ou similares;

(b) uso como material para produção de concreto e argamassas: principais requisitos exigidos aos AR aplicados nesse uso, como absorção à água, densidade e porosidade, resistência ao desgaste à abrasão Los Angeles, teor de cloretos e sulfatos; e

(c) uso como material granular em pavimentação: principais requisitos exigidos aos AR aplicados nesse uso, como índice de forma, CBR e índice de plasticidade.

Tais parâmetros de análise foram definidos com base no padrão de categorização de dados observado na maioria das documentações analisadas.

\section{Resultados e discussões Composição dos agregados}

A Tabela 2 apresenta os parâmetros de classificação e composição dos AR identificados nas prescrições analisadas. A maior parte desses documentos determina de duas a três categorias de classificação para AR, com exceção do Guia Espanhol de Agregados Reciclados (GRÊMIO..., 2012) e da norma nacional alemã DIN 4226-100 (DEUTSCHES..., 2002), que apresentam quatro cada.

Cada especificação possui seus próprios critérios de proporção e denominação das classificações, ainda que sejam observadas algumas tendências. No geral, as classificações se orientam pela proporção de dois conjuntos de componentes presentes no AR - material cerâmico e material cimentício e natural -, sendo assim possível estabelecer uma classificação unificada baseada na composição.

A maioria considera uma classificação equivalente ao ARC, cuja composição deve ter o mínimo de $90 \%$ de resíduos de concreto e/ou agregado natural. A norma espanhola EHE-08 (MINISTERIO..., 2008) e as normas japonesas (MCNEIL; KANG, 2013), por sua vez, por serem normas específicas para produção de concreto, inclusive para fins estruturais, não limitam quantidades mínimas, definindo diretamente que o conteúdo deverá ser majoritariamente desse material, apenas restringindo o conteúdo de material cerâmico para baixas porcentagens.

As classificações consideram ainda diferentes percentuais de cerâmica no agregado, observando-se que na prática essas classificações equivalem a um ARM por considerar, indiretamente, a presença de percentual de material cimentício e natural.

Rilem (1994), em especial, admite que AR mistos devam ter conteúdo de concreto, agregados naturais e materiais betuminosos mínimos de $80 \%$, e que os materiais cerâmicos devem ser limitados a $10 \%$. Isso demonstra maior conservadorismo, que pode ser atribuído ao fato de se tratar de uma norma mais antiga, quando ainda não havia tantos estudos na área. 
Tabela 2 - Classificação e composição do AR por especificação analisada

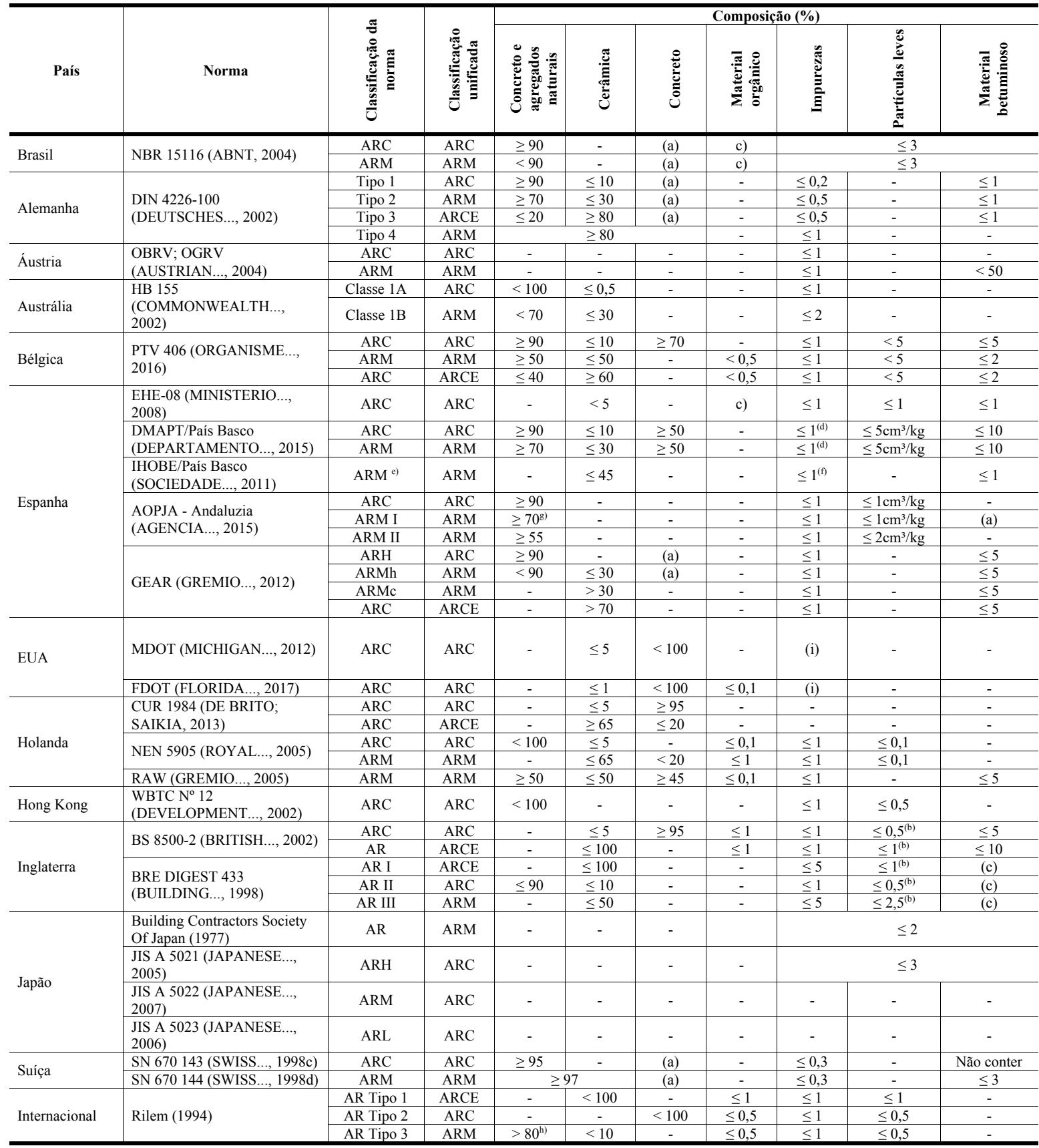

Nota: Legenda:

(a) Incluso no conteúdo de concreto e agregados naturais;

(b) Partículas com densidade $<1.000 \mathrm{~kg} / \mathrm{m}^{3}$;

(c) Incluso no conteúdo de impurezas;

(d) Conteúdo de vidro $\leq 2 \%$;

(e) Válido para aplicaç̃oes em concreto não estrutural;

(f) Conteudo de vidro $\leq 1 \%$; conteudo de gesso $\leq 2,1 \%$;

(g) Conteúdo de material betuminoso incluso;

(h) Conteúdo apenas de agregado natural; e

(i) Incluso no conteúdo de cerâmica. 
Tabela 3 - Requisitos geométricos, físico-mecânicos e químicos de AR para aplicação em concreto

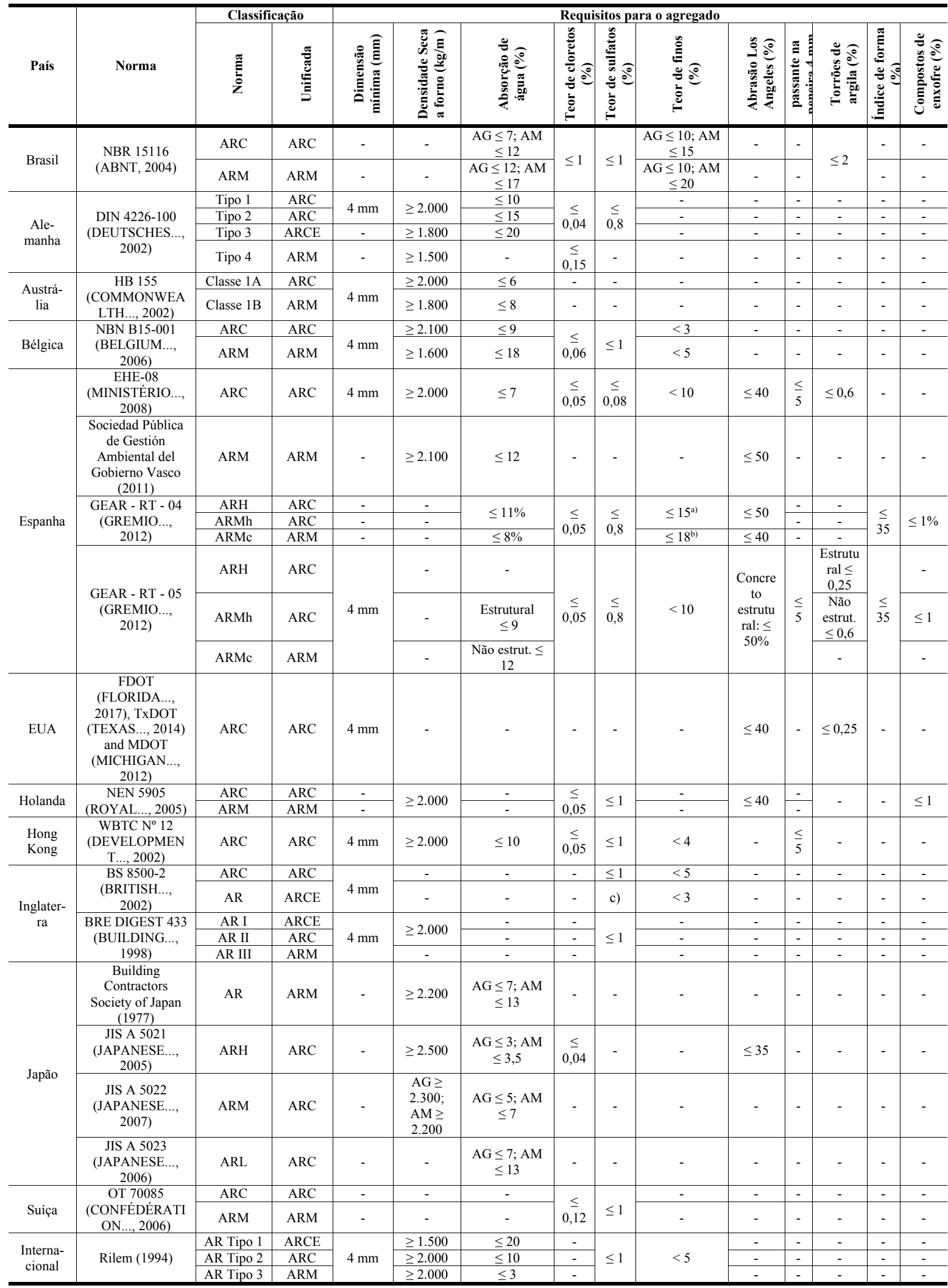

Nota: AG: Agregado graúdo AM: Agregado miúdo;

a) No caso de pré-fabricados de blocos e bancos $\leq 8 \%$;

b) No caso de pré-fabricados de blocos e bancos $\leq 10 \%$;

c) Limites devem ser determinados de forma isolada, caso a caso. 
Nas demais normas e especificações apresentadas na Tabela 2 se observa a tendência das classificações de limitar o conteúdo de material cerâmico entre $30 \%$ e $70 \%$, a exemplo das normas da Austrália (COMMONWEALTH..., 2002), Bélgica (ORGANISME..., 2016), Inglaterra (BUILDING..., 1998), País Basco (SOCIEDAD..., 2011) e Holanda (PELLEGRINO; FALESCHINI, 2016). As especificações da Alemanha (GONÇALVES; BRITO, 2010) e da Bélgica (ORGANISME..., 2016), por sua vez, apresentam classificações que limitam o conteúdo de concreto de $20 \%$ a $40 \%$ e exigem porcentagens mínimas de cerâmica que variam de $65 \%$ a $80 \%$. Nestes casos, essas classificações foram categorizadas como ARCE, pois consideram que a maior parte do agregado é composta desse material.

Quanto à presença de impurezas e contaminantes, a maioria das normas limita o conteúdo a 1\%. A presença de metais, papel, plástico, vidro, madeira, gesso, resíduos vegetais, materiais betuminosos, entre outros, no entanto, pode variar por norma/especificação. A norma alemã admite valor para conteúdo de impurezas mais restrito em relação aos ARC e ARCE (GONÇALVES; BRITO, 2010). Do mesmo modo, as normas suíças também estabelecem limites bem abaixo da maioria das especificações citadas (TAM; SOOMRO; EVANTELISTA, 2018). Em contrapartida, o Japão (GONÇALVES; BRITO, 2010) e o Brasil (ABNT, 2004b) são mais permissivos, possibilitando que o conteúdo de impurezas seja de até $3 \%$, incluindo os materiais betuminosos e orgânicos. Nesse contexto, cabe destacar que a norma brasileira NBR 15116 (ABNT, 2004b) e a norma JIS A 5021 (JAPANESE..., 2005) somente consideram a produção de concretos sem função estrutural.

\section{Uso para produção de concreto e argamassas}

A Tabela 3 apresenta um resumo comparativo dos requisitos exigidos nas normativas e especificações técnicas analisadas para AR a serem aplicados em concreto.

A maior parte dos documentos analisados indica limites para o conteúdo de finos dos AR, que variam muito segundo normativa, tipo de agregado e uso. Países como Reino Unido (BUILDING..., 1998; BRITISH..., 2006), Hong Kong (DEVELOPMENT..., 2002), Bélgica (TAM; SOOMRO; EVANGELISTA, 2018) e a especificação do Rilem (RILEM, 1994) admitem máximos que variam de 3\% a 5\%, enquanto Brasil (ABNT, 2004b) e Espanha (GRÊMIO..., 2012) impõem limites maiores. Na Espanha, em especial, observam-se limites de $15 \%$ a $18 \%$ de material passante na peneira $0,0063 \mathrm{~mm}$ para usos em pré-fabricados (GRÊMIO..., 2012). A exceção é dada pelas normativas da Alemanha (GONÇALVES; BRITO, 2010), Suíça (TAM; SOOMRO; EVANGELISTA, 2018), Holanda (PELLEGRINO; FALESCHINI, 2016), EUA (MICHIGAN..., 2012; TEXAS..., 2014; FLORIDA..., 2017), Austrália (COMMONWEALTH..., 2002) e Japão (GONÇALVES; BRITO, 2010), que não apresentam limitações para esse parâmetro.

Para o parâmetro de densidade mínima, os limites estabelecidos variam de 2.000 a $2.500 \mathrm{~kg} / \mathrm{m}$ para ARC, e de 1.500 a $2.000 \mathrm{~kg} / \mathrm{m}$ para ARM. A exceção é feita por normativas e especificações da Alemanha (GONÇALVES; BRITO, 2010), Espanha (GRÊMIO..., 2012; MINISTERIO..., 2008; SOCIEDAD..., 2011), Holanda (PELlEGRINO; FALESCHINI, 2016), Hong Kong (DEVELOPMENT..., 2002) e Austrália (COMMONWEALTH..., 2002), que estabeleceram valores mínimos de $\geq 2.000 \mathrm{~kg} / \mathrm{m}$ para o ARC.

As normativas japonesas, por outro lado, se tornam mais exigentes de acordo com o uso. A norma JIS A 5021 (JAPANESE..., 2005) se destina a concretos de até $40 \mathrm{MPa}$, enquanto a JIS A 5022 (2006) se destina a concretos de resistências menores, e a JIS A 5023 (JAPANESE..., 2006), a concretos sem função estrutural.

A absorção de água em agregados, por sua vez, está intimamente relacionada com sua densidade, e por isso este também é um parâmetro muito relevante nas especificações comparadas. As normas mais restritivas admitem valores máximos de absorção de 5\% a 8\%: Espanha (GRÊMIO..., 2012; MINISTERIO..., 2008), Japão (GONÇALVES; BRITO, 2010), Austrália (COMMONWEALTH..., 2002) e Brasil (ABNT, 2004b). As mais permissivas admitem valores máximos de 9\% a 20\%: Hong Kong (DEVELOPMENT..., 2002), Bélgica (TAM; SOOMRO; EVANGELISTA, 2018), Alemanha (GONÇALVES; BRITO, 2010) e as especificações do Rilem (RILEM, 1994).

Em relação aos ARM, de modo geral, as especificações são menos rigorosas, e os valores variam entre $8 \%$ e 20\%. O único valor que destoa das demais especificações é o admitido pelo Rilem (RILEM, 1994) para AR do tipo $3(\leq 3 \%)$. Isso porque esse tipo de agregado, como visto na Tabela 2 , tem apenas $10 \%$ de elementos cerâmicos em sua composição. As normas britânicas (BUILDING..., 1998; BRITISH..., 2006), suíças (TAM; SOOMRO; EVANGELISTA, 2018) e americanas (MICHIGAN..., 2012; TEXTAS..., 2014; FLORIDA..., 2017), por sua vez, não abordam essa propriedade, pois admitem que os parâmetros de composição permitidos devem ser suficientes para garantir a qualidade. 
Quando à resistência à abrasão, apesar de ser um parâmetro consideravelmente importante para o concreto, apenas as normas espanholas, holandesas e americanas, além da norma japonesa JIS A 5021 (JAPANESE..., 2005), abordam limites de coeficiente de Los Angeles, variando entre $40 \%$ e $50 \%$.

O teor de sulfatos, por outra parte, é um parâmetro exigido em praticamente todos esses documentos. A diferença se encontra no tipo de ensaio adotado para sua determinação. Os valores máximos variam entre $0,8 \%$ e $1 \%$, sendo as normativas alemã (GONÇALVES; BRITO, 2010) e espanholas (GRÊMIO..., 2012; MINISTERIO..., 2008) as mais restritivas. Países como Japão (GONÇALVES; BRITO, 2010), Austrália (COMMONWEALTH..., 2002) e EUA (MICHIGAN..., 2012; TEXAS..., 2014; FLORIDA..., 2017) não mencionam limites para esse parâmetro.

Quanto à presença de cloretos, os valores são: 0,04\% na Alemanha e Japão (GONÇALVES; BRITO, 2010); 0,05\% na Espanha (GRÊMIO..., 2012; MINISTERIO..., 2008), Holanda (PELLEGRINO; FALESCHINI, 2016) e Hong Kong (DEVELOPMENT..., 2002); e 0,06\% na Bélgica (TAM; SOOMRO; EVANGELISTA, 2018). A norma suíça e a alemã apresentam valores ligeiramente maiores para ARM, contudo o maior contraste se encontra no valor máximo admitido pela NBR 15116 (ABNT, 2004b), que é o único documento que permite que tal parâmetro chegue a $1 \%$.

Observa-se que a variação de limites em alguns parâmetros analisados ocorre por influência da aplicação prevista para o concreto em norma (uso estrutural ou não estrutural, e classes de resistência permitidas).

A Tabela 4 compara os documentos no âmbito da aplicação em concretos. Muitos dos documentos não consideram agregados miúdos para concreto, estabelecendo o limite mínimo de $4 \mathrm{~mm}$ de dimensão do agregado. Atribui-se a situação à usual dificuldade das linhas de produção de AR em separar contaminantes existentes nas frações mais finas do resíduo de entrada.

Quanto ao percentual de substituição, a maioria dos documentos só admite a substituição de $20 \%$ do agregado graúdo natural por ARC. Alguns documentos, no entanto, são mais permissivos, como a norma alemã DAfStb (GONÇALVES; BRITO, 2010), que admite a aplicação de até $45 \%$ de AR, a depender do tipo de agregado, classe de exposição e limites de resistência, e a inglesa BS 8500-2 (BRITISH..., 2006), que admite a substituição na fração graúda em até $100 \%$.

A especificação Rilem (RILEM, 1994), em especial, mesmo sendo um dos documentos mais antigos, admite a substituição de até $100 \%$ para ambientes secos e úmidos sem exposição química agressiva, e, inclusive, considera classes de resistência altas para concretos produzidos com ARC. Essa orientação pode ser atribuída ao fato de a especificação considerar fatores de correção para as propriedades dos concretos reciclados. A especificação espanhola GEAR-RT-04, por sua vez, permite a utilização de $20 \%$ a $100 \%$ em pré-fabricados de concreto desde que expostos a condições climáticas favoráveis (GRÊMIO..., 2012).

Boa parte das especificações restringe o uso de concreto reciclado a ambientes não agressivos quimicamente (classes de exposição $\mathrm{X} 0$ e XC1, características de ambientes internos ou na terra sem exposição ao congelamento, secos ou, no máximo, úmidos, sem risco de corrosão ou ataque químico). A norma alemã pode ser considerada ligeiramente mais permissiva por aceitar o uso de AR em concretos expostos a ambientes mais agressivos; no entanto, à medida que os riscos ambientais se tornam maiores, a especificação restringe mais os limites de substituição do agregado natural (GONÇALVES; BRITO, 2010).

Quanto ao uso em argamassas, observa-se que a maior parte das prescrições considera a aplicação de AR em concretos, e, nesse sentido, excluem o uso da fração miúda. Os documentos que não coíbem o uso da fração miúda são permissíveis ao uso do agregado miúdo reciclado tanto para aplicação em concreto quanto para a produção de argamassas. Por outro lado, muito desses simplesmente não distinguem os requisitos exigidos para concretos e para argamassas, como é o caso das normas do Brasil (ABNT, 2004b), Alemanha (GONÇALVES; BRITO, 2010), Suíça (TAM; SOOMRO; EVANGELISTA, 2018), Japão (GONÇALVES; BRITO, 2010) e Holanda (PELLEGRINO; FALESCHINI, 2016).

A especificação belga foi o único documento analisado que apresentou recomendações direcionadas para o uso do agregado miúdo reciclado. Nesse documento são estabelecidos requisitos para contaminantes flutuantes $\leq 7,5 \mathrm{ml} / \mathrm{kg}$; impurezas $\leq 1,0 \%(\mathrm{~m} / \mathrm{m})$; teor de vidro $\leq 2,0 \%(\mathrm{~m} / \mathrm{m})$; teor de partículas finas $(<$ $0,063 \mathrm{~mm})<15 \%$; e matéria orgânica $\leq 1,0 \%$. Considerando uma substituição de até $50 \%$ da areia, as propriedades exigidas são as mesmas, com exceção do teor de partículas finas, que pode atingir $25 \%$. Além disso, o método exigido para determinação da qualidade das partículas finas é o ensaio de adsorção de azul de metileno de acordo com a norma NBN EN 933-9 (EUROPEAN..., 2009), que estabelece o limite de 8 $\mathrm{g} / \mathrm{kg}$ (ORGANISME..., 2016). 
Ambiente Construído, Porto Alegre, v. 21, n. 3, p. 305-320, jul./set. 2021.

Tabela 4 - Condições de aplicação de AR em concreto por especificação analisada

\begin{tabular}{|c|c|c|c|c|c|c|c|c|}
\hline \multirow[b]{2}{*}{ País } & \multirow[b]{2}{*}{ Norma } & \multicolumn{2}{|c|}{ Classificação } & \multirow[b]{2}{*}{ Aplicação } & \multicolumn{2}{|c|}{ Substituição (\%) } & \multirow[b]{2}{*}{ Condições de uso } & \multirow{2}{*}{$\begin{array}{c}\text { Resistência } \\
\text { máxima (ou } \\
\text { classe) do } \\
\text { concreto } \\
\text { produzido }\end{array}$} \\
\hline & & $\begin{array}{c}\text { Nor- } \\
\text { ma }\end{array}$ & $\begin{array}{l}\text { Unifi- } \\
\text { cada }\end{array}$ & & $\begin{array}{l}\text { Agrega- } \\
\text { do } \\
\text { graúdo }\end{array}$ & $\begin{array}{l}\text { Agrega- } \\
\text { do miúdo }\end{array}$ & & \\
\hline \multirow{2}{*}{ Brasil } & \multirow{2}{*}{$\begin{array}{l}\text { NBR } 15116 \text { (ABNT, } \\
\text { 2004) }\end{array}$} & $\mathrm{ARC}$ & $\mathrm{ARC}$ & \multirow{2}{*}{$\begin{array}{l}\text { Não } \\
\text { estrutural }\end{array}$} & \multirow{2}{*}{\multicolumn{2}{|c|}{$\leq 100$}} & - & \multirow{2}{*}{$\mathrm{C} 15$} \\
\hline & & ARM & ARM & & & & - & \\
\hline \multirow{4}{*}{ Alemanha } & \multirow{4}{*}{$\begin{array}{l}\text { DIN 4226-100 } \\
\text { (DEUTSCHES..., } \\
\text { 2002) }\end{array}$} & Tipo 1 & $\mathrm{ARC}$ & \multirow[b]{2}{*}{ Estrutural } & $\leq 45$ & 0 & \multirow{2}{*}{$\begin{array}{l}\text { Classes de exposição X0, } \\
\text { XC1 a XC4, XF1-XF3, } \\
\text { XA1. Não é permitido o uso } \\
\text { em concreto protendido }\end{array}$} & \multirow[b]{2}{*}{$35 \mathrm{MPa}$} \\
\hline & & Tipo 2 & $\mathrm{ARC}$ & & $\leq 35$ & 0 & & \\
\hline & & Tipo 3 & ARCE & \multirow{2}{*}{$\begin{array}{l}\text { Não } \\
\text { estrutural e } \\
\text { argamassas }\end{array}$} & \multicolumn{2}{|c|}{-} & \multirow{2}{*}{$\begin{array}{l}\text { Concreto sem função } \\
\text { estrutural e argamassas }\end{array}$} & - \\
\hline & & Tipo 4 & ARM & & & - & & - \\
\hline \multirow[b]{2}{*}{ Austrália } & \multirow{2}{*}{$\begin{array}{l}\text { HB } 155 \\
\text { (COMMONWEALT } \\
\text { H..., 2002) }\end{array}$} & $\begin{array}{l}\text { Classe } \\
1 \mathrm{~A}\end{array}$ & $\mathrm{ARC}$ & & $\leq 30$ & 0 & \multirow{2}{*}{$\begin{array}{l}\text { Concretos estruturais com } \\
\text { ajustes de dosagens, } \\
\text { permeabilidade e } \\
\text { propriedades e } \\
\text { encolhimento inferiores }\end{array}$} & $40 \mathrm{MPa}$ \\
\hline & & $\begin{array}{l}\text { Classe } \\
1 \mathrm{~B}\end{array}$ & ARM & Concreto & $\leq 100$ & 0 & & $25 \mathrm{MPa}$ \\
\hline \multirow{2}{*}{ Bélgica } & \multirow{2}{*}{$\begin{array}{l}\text { NBN B15-001 } \\
\text { (BELGIUM..., } \\
2006)\end{array}$} & $\mathrm{ARC}$ & $\mathrm{ARC}$ & Estrutural & $\leq 20$ & 0 & $\begin{array}{l}\text { Classes de exposição X0 e } \\
\text { XC1 }\end{array}$ & $\mathrm{C} 30 / \mathrm{C} 7$ \\
\hline & & ARM & ARM & $\begin{array}{l}\text { Não } \\
\text { estrutural }\end{array}$ & $\leq 100$ & 0 & ( & $\mathrm{C} 16 / 20$ \\
\hline & $\begin{array}{l}\text { EHE-08 } \\
\text { MINISTERIO }\end{array}$ & $\mathrm{ARC}$ & $\mathrm{ARC}$ & Estrutural & $\leq 20$ & 0 & $\begin{array}{l}\text { Exceto em concreto } \\
\text { protendido }\end{array}$ & $40 \mathrm{MPa}$ \\
\hline & 2008) & & & $\begin{array}{l}\text { Não } \\
\text { estrutural }\end{array}$ & $\leq 100$ & 0 & - & - \\
\hline Espanha & $\begin{array}{l}\text { Sociedad Pública De } \\
\text { Gestión Ambiental } \\
\text { Del Gobierno Vasco } \\
\text { (2011) }\end{array}$ & ARM & ARM & $\begin{array}{l}\text { Não } \\
\text { estrutural }\end{array}$ & & 100 & ${ }^{2}$ & $\mathrm{C} 15$ \\
\hline Espanna & & $\mathrm{ARH}$ & $\mathrm{ARC}$ & & & - & Condições climáticas & - \\
\hline & GEAR - RT - 04 & ARMh & $\mathrm{ARC}$ & fabricados de & 20 a 100 & - & favoráveis e sem exposição & - \\
\hline & (GREMIO..., 2012) & ARMc & ARM & concreto & $20 \mathrm{a} 100$ & - & $\begin{array}{l}\text { ao congelamento e } \\
\text { descongelamento }\end{array}$ & - \\
\hline & & ARH & $\mathrm{ARC}$ & & & - & - & Estrutural: 30 \\
\hline & GEAR - RT - 05 & ARMh & ARC & Misturas & & - & - & MPa; Não \\
\hline & (GREMIO..., 2012) & ARMc & ARM & para concreto & & - & - & $\begin{array}{l}\text { estrutural: } 20 \\
\mathrm{MPa}\end{array}$ \\
\hline & $\begin{array}{l}\text { FDOT } \\
\text { (FLORIDA..., 2017) }\end{array}$ & $\mathrm{ARC}$ & $\mathrm{ARC}$ & $\begin{array}{l}\text { Não } \\
\text { estrutural }\end{array}$ & - & - & - & - \\
\hline EUA & $\begin{array}{l}\text { TxDOT (TEXAS..., } \\
\text { 2014) }\end{array}$ & $\mathrm{ARC}$ & $\mathrm{ARC}$ & $\begin{array}{l}\text { Não } \\
\text { estrutural }\end{array}$ & - & - & - & - \\
\hline & $\begin{array}{l}\text { MDOT } \\
\text { (MICHIGAN..., } \\
\text { 2012) }\end{array}$ & $\mathrm{ARC}$ & $\mathrm{ARC}$ & $\begin{array}{l}\text { Não } \\
\text { estrutural }\end{array}$ & - & - & - & - \\
\hline & NEN 5905 & $\mathrm{ARC}$ & $\mathrm{ARC}$ & & $\leq 100$ & - & Condições climáticas & $\mathrm{C} 40 / \mathrm{C} 50$ \\
\hline Holanda & (ROYAL..., 2005) & ARM & ARM & Concreto & & - & $\begin{array}{l}\text { favoráveis e ambientes não } \\
\text { agressivos }\end{array}$ & $20 \mathrm{MPa}$ \\
\hline Hong & WBTC N $^{\circ} 12$ & & & Estrutural & $\leq 20$ & 0 & - & $35 \mathrm{Mpa}$ \\
\hline $\begin{array}{l}\text { Hong } \\
\text { Kong }\end{array}$ & $\begin{array}{l}\text { (DEVELOPMENT.. } \\
., 2002)\end{array}$ & $\mathrm{ARC}$ & $\mathrm{ARC}$ & $\begin{array}{l}\text { Não } \\
\text { estrutural }\end{array}$ & $\leq 100$ & 0 & ( & $20 \mathrm{MPa}$ \\
\hline & BS 8500-2 & $\mathrm{ARC}$ & $\mathrm{ARC}$ & Estrutural & $\leq 100$ & 0 & Classes de exposição X0, & $\mathrm{C} 40 / 50$ \\
\hline & (BRITISH..., 2002) & $\mathrm{AR}$ & ARCE & Não & $\leq 20$ & 0 & $\begin{array}{l}\mathrm{XC} 1, \mathrm{XC} 3, \mathrm{XC} 4, \mathrm{XF} 1, \mathrm{DC}- \\
1\end{array}$ & $\mathrm{C} 16 / 20$ \\
\hline Inglaterra & BRE DIGEST & AR I & ARCE & & - & 0 & - & $\mathrm{C} 20$ \\
\hline & 433(BUILDING..., & AR II & ARC & Estrutural & - & 0 & - & $\mathrm{C} 35$ \\
\hline & 1998) & AR III & ARM & Concretos & $\leq 20$ & 0 & - & - \\
\hline & $\begin{array}{l}\text { Building Contractors } \\
\text { Society of Japan } \\
\text { (1977) }\end{array}$ & AR & ARM & $\begin{array}{l}\text { Não } \\
\text { estrutural }\end{array}$ & & 100 & Elementos de fundação & $18 \mathrm{MPa}$ \\
\hline & JIS A 5021 (2005) & $\mathrm{ARH}$ & $\mathrm{ARC}$ & & & - & - & $45 \mathrm{MPa}$ \\
\hline Japão & $\begin{array}{l}\text { JIS A } 5022 \\
\text { (JAPANESE..., } \\
\text { 2006) }\end{array}$ & ARM & $\mathrm{ARC}$ & Estrutural & & - & $\begin{array}{l}\text { Não expostos ao gelo e ao } \\
\text { degelo }\end{array}$ & - \\
\hline & $\begin{array}{l}\text { JIS A } 5023 \\
\text { (JAPANESE..., } \\
2007) \\
\end{array}$ & ARL & $\mathrm{ARC}$ & $\begin{array}{l}\text { Não } \\
\text { estrutural }\end{array}$ & & 100 & - & - \\
\hline & OT 70085 & $\mathrm{ARC}$ & $\mathrm{ARC}$ & & & & - & - \\
\hline Suíça & $\begin{array}{l}\text { (JAPANESE..., } \\
2006)\end{array}$ & ARM & ARM & Concreto & & 100 & - & - \\
\hline $\begin{array}{l}\text { Interna- } \\
\text { cional }\end{array}$ & RILEM (1994) & $\begin{array}{l}\text { AR } \\
\text { Tipo } 1\end{array}$ & ARCE & Concreto & $\leq 100$ & $\begin{array}{l}\text { Não } \\
\text { recomen- } \\
\text { dado }\end{array}$ & $\begin{array}{l}\text { Ambientes secos e úmidos } \\
\text { sem exposição química } \\
\text { agressiva }\end{array}$ & $\mathrm{C} 16 / 20$ \\
\hline
\end{tabular}

314 Alberte, E. P. V.; Handro, J. B. 
A Tabela 5 apresenta um resumo comparativo dos requisitos identificados para AR a serem aplicados em argamassa.

\section{Uso para produção de pavimentos}

Todas as prescrições observam requisitos para o uso de AR na execução de camadas granulares de pavimentos diversos, destacando-se os parâmetros de resistência à abrasão e de Índice de Suporte Califórnia (ISC) como os mais citados. Serviços de terraplenagem, aterros, nivelamentos topográficos, enchimentos e obras de drenagens também são abordados em algumas prescrições, a exemplo das normas espanholas (GRÊMIO..., 2012; SOCIEDAD..., 2011; AGENCIA..., 2015), holandesa (GRÊMIO..., 2005), suíça (SWISS..., 1998a, 1998b, 1998c, 1998d), australiana (INSTITUTE..., 2010) e norte-americanas (MICHIGAN..., 2012; TEXAS..., 2014; FLORIDA..., 2017).

A Tabela 6 apresenta os principais requisitos abordados nesses documentos para o uso de AR em pavimentos.

Os documentos espanhóis são mais específicos ao considerar categorias de tráfego. No entanto, essa é uma classificação de caráter particular, que pode variar segundo cada país.

Grande parte dos documentos define a granulometria do AR, sendo a normativa brasileira a que permite a maior dimensão máxima de agregado.

Sobre índice de forma, os parâmetros encontrados são diferentes. A norma europeia EN 933-4 considera o quociente da massa das partículas não cúbicas (comprimento/espessura do grão > 3) pela massa da amostra. Já a norma NBR 7809 (ABNT, 2006) considera índice de forma como a relação entre o comprimento e a espessura dos grãos do agregado (ABNT, 2006).

Tabela 5 - Requisitos geométricos, físico-mecânicos e químicos de AR para aplicação em argamassa

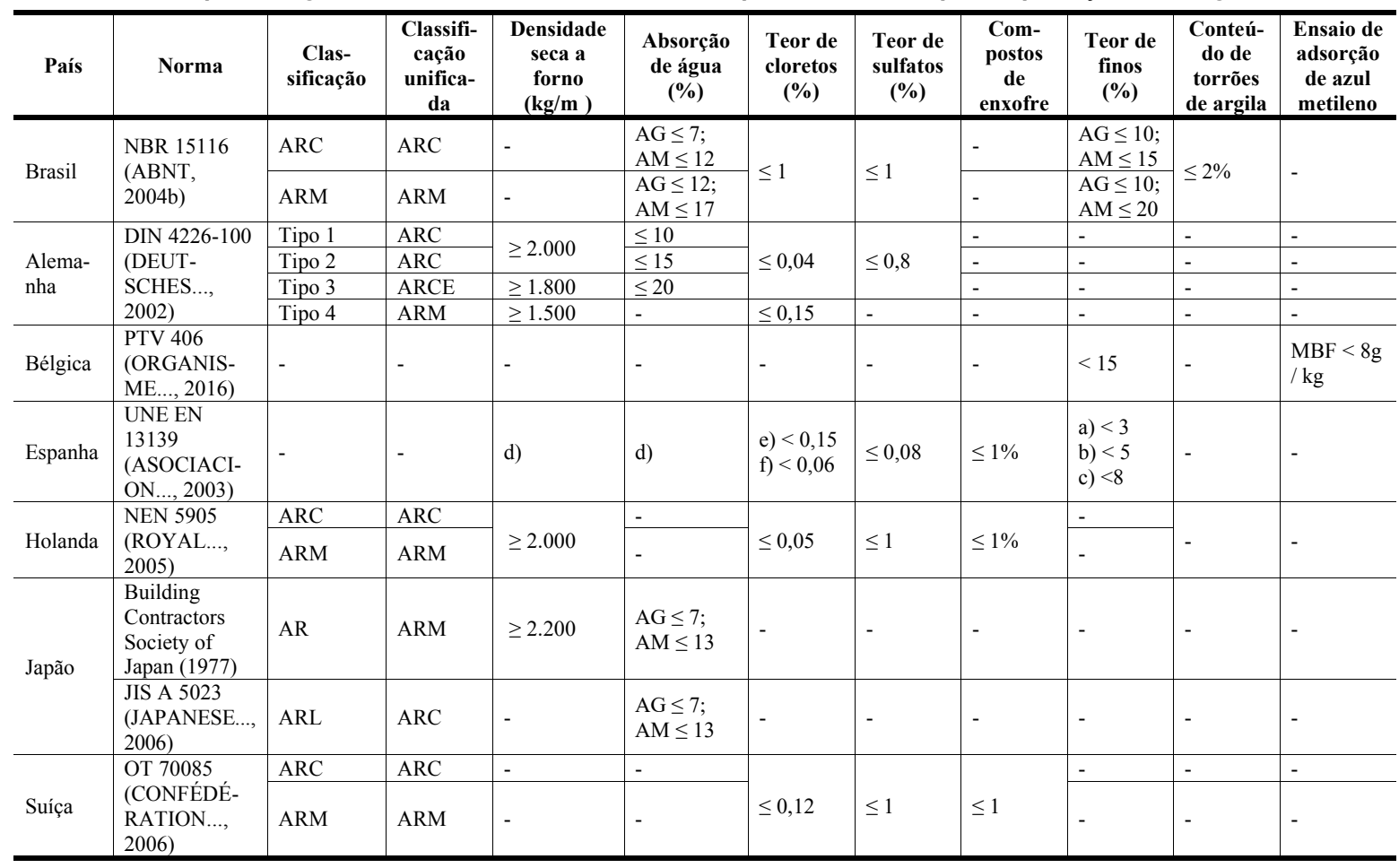


Tabela 6 - Requisitos técnicos para AR aplicados em pavimentos

\begin{tabular}{|c|c|c|c|c|c|c|c|c|c|c|}
\hline País & $\begin{array}{l}\text { Clas- } \\
\text { sificação }\end{array}$ & & plicações & $\begin{array}{c}\text { Índice } \\
\text { de } \\
\text { Forma } \\
(\%) \\
\end{array}$ & $\begin{array}{l}\text { Abrasão Los } \\
\text { Angeles (\%) }\end{array}$ & $\begin{array}{l}\text { Absorção } \\
\text { de água } \\
(\%)\end{array}$ & $\begin{array}{l}\text { Equival } \\
\text { e-nte de } \\
\text { areia }\end{array}$ & $\begin{array}{l}\text { ISC } \\
(\%)\end{array}$ & $\begin{array}{c}\text { Teor de } \\
\text { sulfatos } \\
(\%)\end{array}$ & Plasticidade \\
\hline \multirow[t]{2}{*}{ Brasil } & \multirow[t]{2}{*}{$\begin{array}{l}\text { ARC e } \\
\text { ARM }\end{array}$} & \multicolumn{2}{|c|}{\begin{tabular}{|l|} 
Reforço de subleito \\
Sub-base de pavimento e \\
revestimento primário \\
\end{tabular}} & \multirow[t]{2}{*}{$<3^{*}$} & - & & - & $\geq 20$ & \multirow[t]{2}{*}{$\leq 2$} & - \\
\hline & & Base de pavi & ento & & - & - & - & $\geq 60$ & & - \\
\hline Alemanha & $\begin{array}{l}\text { ARC e } \\
\text { ARM }\end{array}$ & Pavimento $\mathrm{d}$ & concreto & $\leq 50$ & $\leq 32$ & $\leq 0,5$ & - & - & - & - \\
\hline \multirow{3}{*}{ Austrália } & $\begin{array}{l}\text { AR Classe } \\
\text { I }\end{array}$ & \multirow{3}{*}{\multicolumn{2}{|c|}{$\begin{array}{l}\text { Pavimentação, serviços de } \\
\text { terraplenagem }\end{array}$}} & - & $\leq 30$ & - & - & - & - & $\mathrm{LL}<25 ; \mathrm{IP}<6$ \\
\hline & $\begin{array}{l}\text { AR Classe } \\
\text { II }\end{array}$ & & & - & \multirow{2}{*}{$\leq 45$} & - & - & - & - & $\mathrm{LL}<28 ;$ IP $<8$ \\
\hline & $\begin{array}{l}\text { AR Classe } \\
\text { III }\end{array}$ & & & - & & - & - & - & - & $\begin{array}{l}\mathrm{LL}<35 ; \mathrm{IP}< \\
15\end{array}$ \\
\hline \multirow{4}{*}{ Espanha } & $\begin{array}{l}\mathrm{ARC} \text { e } \\
\mathrm{ARM}\end{array}$ & \multicolumn{2}{|c|}{$\begin{array}{l}\text { Serviços de terraplenagem e } \\
\text { aterros }\end{array}$} & - & ses & - & $>30$ & $\begin{array}{l}\text { a) }>20 \\
\text { b) }>40\end{array}$ & $\begin{array}{l}\text { c) }<0,2 \\
\text { d) }<0,7\end{array}$ & - \\
\hline & $\mathrm{ARC}$ & \multirow{2}{*}{$\begin{array}{l}\text { Camadas } \\
\text { granulares } \\
\text { de } \\
\text { pavimento }\end{array}$} & $\begin{array}{l}\text { Bica corrida } \\
\text { reciclada de } \\
\text { concreto em vias de } \\
\text { tráfego T2 a T4 }\end{array}$ & \multirow{3}{*}{$\leq 35$} & $\begin{array}{l}\text { T2: }<35 ; \text { T3 e } \\
\text { T4, Ciclovias } \\
\text { e passeios: }< \\
40\end{array}$ & $\begin{array}{l}\text { AG: }<7 \\
\mathrm{AM}<7\end{array}$ & $>35$ & \multirow{2}{*}{$>40$} & \multirow{3}{*}{$\begin{array}{l}\text { c) }<0,5 \\
\text { d) }<0,7\end{array}$} & \multirow[t]{2}{*}{-} \\
\hline & ARM I & & $\begin{array}{l}\text { Bica corrida } \\
\text { reciclada mista I em } \\
\text { vias de tráfego T2 a } \\
\mathrm{T} 4\end{array}$ & & $\begin{array}{l}\text { T3 e T4, } \\
\text { Ciclovias e } \\
\text { passeios: }<40\end{array}$ & $\begin{array}{l}\mathrm{AG}:<9 \\
\mathrm{AM}<12\end{array}$ & $>30$ & & & \\
\hline & ARM II & $\begin{array}{l}\text { Sub-base de } \\
\text { pavimento }\end{array}$ & $\begin{array}{l}\text { Bica corrida } \\
\text { reciclada mista II } \\
\text { em vias de tráfego } \\
\text { T4 }\end{array}$ & & $\begin{array}{l}\text { T4, Ciclovias } \\
\text { e passeios: }< \\
40\end{array}$ & $\begin{array}{l}\text { AG: }<11 \\
\mathrm{AM}<14\end{array}$ & $>25$ & $>20$ & & $\mathrm{LL}<25 ; \mathrm{IP}<6$ \\
\hline
\end{tabular}

Nota: Legenda:

LL: Limite de liquidez; e

IP: Índice de plasticidade.

A NBR 15115 (ABNT, 2004a) admite até 30\% de grãos lamelares. Esse limite pode ser comparado com os valores de índice de forma especificados pelas prescrições espanholas (GRÊMIO..., 2012; SOCIEDAD..., 2011; AGENCIA..., 2015) e pela norma alemã (ROAD..., 2004). A normativa brasileira se apresenta mais exigente em relação aos demais documentos, seguida das prescrições espanholas e da normativa alemã.

Quanto à resistência à abrasão, os limites exigidos apresentam valores variáveis. As prescrições espanholas (GRÊMIO..., 2012; SOCIEDAD..., 2011; AGENCIA..., 2015) especificam esse parâmetro segundo a classificação do tráfego, indicando limites mais restritivos para categorias de fluxo de veículos maiores. A Holanda (GRÊMIO..., 2005) e os EUA (MICHIGAN..., 2012; TEXAS..., 2014; FLORIDA..., 2017), por sua vez, indicam valores mais altos em comparação a outros países, enquanto a maior parte determina limites entre $30 \%$ e $45 \%$.

De modo similar, os limites de ISC identificados também tendem a variar segundo o uso e a demanda do pavimento. A norma brasileira (ABNT, 2004a) estabelece valores de CBR distintos conforme o uso do pavimento. $\mathrm{O}$ valor mínimo de ISC aumenta à medida que a camada feita com AR se aproxima da capa de rodagem do pavimento.

\section{Considerações finais}

Os resultados indicam as diferentes abordagens adotadas por países para a regulamentação do uso do AR em diversas aplicações, identificando tendências e convergências quanto à composição dos agregados, requisitos geométricos, físicos, mecânicos e químicos exigidos, e ações de controle de qualidade seguidas. 
As normas aplicáveis a concreto apresentam similaridades quanto aos requisitos físicos, mecânicos e químicos exigidos. A depender do tipo de aplicação considerado (concreto não estrutural, estrutural, préfabricados, entre outros), as exigências são mais ou menos permissivas. Diante disso, a regulamentação de uso de AR em concreto pode instituir limites tanto no percentual de substituição de AR, quanto nas condições de aplicação do concreto relacionadas às classes de exposição ambientais e às resistências mínimas exigidas.

Não foram encontrados requisitos específicos para uso de AR em argamassas em quantidade comparável com os encontrados para uso em concretos e pavimentos. Identifica-se uma clara lacuna de especificações nessa área no país, principalmente ao observar que a maioria das especificações de uso do AR em concreto se restringe a utilizar a fração grossa do material. Evidencia-se aqui a importância em fomentar o uso do AR miúdo, com vistas a garantir sustentabilidade ao processo de reciclagem.

A maioria dos países possui especificações para uso do AR na execução de bases e sub-bases de pavimentos, sendo esse o maior foco de suas normatizações. Considerando a aplicação em pavimentos, terraplenagem, drenagens, enchimento de valas e aterros, os documentos indicam maior aceitação de uso do AR, desde que o pavimento não seja submetido a elevadas cargas ou a tráfegos pesados.

Países como Espanha, Japão e Alemanha já se encontram avançados no tema, podendo se tornar modelos para o crescimento do mercado do AR no Brasil. E as normas brasileiras têm conteúdo alinhado com as especificações analisadas. Por outro lado, as normas necessitam constante atualização, de modo a minimizar suas limitações. Nesse sentido, nota-se que as normativas brasileiras têm mais de 15 anos de antiguidade e devem ser revistas conforme o estado do conhecimento atual.

Finalmente, outra lacuna evidenciada se refere ao desenvolvimento de normas mais detalhadas, voltadas a direcionar o processo executivo, desde usos mais simples, como material granular para pavimentação, até usos mais nobres, como concreto estrutural. Manuais e guias direcionados para produtores e consumidores abordam não só diretrizes técnicas como também recomendações construtivas para cada serviço específico, e são diferenciais de alguns países, como a Espanha.

\section{Referências}

AFFONSO, F. J. A. Caracterização de agregados reciclados de resíduos de construção e demolição para uso em camadas drenantes de aterros sanitários. Rio de Janeiro, 2005. Tese (Mestrado em Ciências em Engenharia Civil) - Instituto Alberto Luiz Coimbra de Pós-Graduação e Pesquisa de Engenharia, Universidade Federal do Rio de Janeiro, Rio de Janeiro, 2005.

AGENCIA DE OBRA PÚBLICA DE LA JUNTA DE ANDALUCÍA. Guía de áridos reciclados de residuos de construcción y demolición (RCD) de Andalucía Central. Andalucía, 2015.

ASOCIACIÓN ESPAÑOLA DE NORMALIZACIÓN Y CERTIFICACIÓN. UNE EN 13139: áridos para morteros. Madrid. 2003.

ASSOCIAÇÃO BRASILEIRA DE EMPRESAS DE LIMPEZA PÚBLICA E RESÍDUOS ESPECIAIS. Panorama dos resíduos sólidos no Brasil 2017. São Paulo, 2017.

ASSOCIAÇÃO BRASILEIRA DE NORMAS TÉCNICAS. NBR 15115: agregados reciclados de resíduos sólidos da construção civil: execução de camadas de pavimentação: procedimentos. Rio de Janeiro, 2004a.

ASSOCIAÇÃO BRASILEIRA DE NORMAS TÉCNICAS. NBR 15116: agregados reciclados de resíduos sólidos da construção civil: utilização em pavimentação e preparo de concreto sem função estrutural: requisitos. Rio de Janeiro, 2004b.

ASSOCIAÇÃO BRASILEIRA DE NORMAS TÉCNICAS. NBR 7809: Agregado graúdo: determinação do índice de forma pelo método do paquímetro: método de ensaio. Rio de Janeiro, 2006.

\section{AUSTRIAN CONSTRUCTION MATERIALS RECYCLING ASSOCIATION. Guidelines for recycled} construction material. Wien, 2004.

BELGIUM STANDARD. NBN B 15-001: concrete - Specification, performance, production and conformity. Brussels, 2006.

BRITISH STANDARDS INSTITUTION. BS 8500-2: concrete: complementary British Standard to BS EN 206-1: specification for constituent materials and concrete. London, 2006. 
BUILDING CONTRACTORS SOCIETY OF JAPAN. Proposed standard for the use of recycled aggregate and recycled aggregate concrete. Tokyo, 1977.

BUILDING RESEARCH ESTABLISHMENT. BRE Digest 433: recycled aggregates. London, 1998.

COMMONWEALTH SCIENTIFIC AND INDUSTRIAL RESEARCH ORGANISATION. HB 155: guide to the use of recycled concrete and masonry materials. Sidney, 2002.

CONFÉDÉRATION SUISSE. OT 70085: instruction technique: utilisation de matériaux de construction minéraux secondaires dans la construction d'abris. Berne, 2006.

CONSELHO NACIONAL DO MEIO AMBIENTE. Resolução n 307, de 5 de julho de 2002. Diário Oficial da União, de 30 de agosto de 2002, seção I, p. 17.241. Brasília, 2002.

CUNHA, N. A. Resíduos da construção civil: análise de usinas de reciclagem. Campinas, 2007. Dissertação (Mestrado em Engenharia Civil) - Faculdade de Engenharia Civil Arquitetura e Urbanismo, Universidade Estadual de Campinas, Campinas, 2007.

CUR AANBEVELING. Betonpuingranulaaten als Toeslagsmateriaal vor Beton. CURVB. 'sHertogenbosch, 1984.

DE BRITO, J.; SAIKIA, N. recycled aggregate in concrete: use of industrial, construction and demolition waste. London: Green Energy and Technology, 2013.

DEPARTAMENTO DE MEDIO AMBIENTE Y POLITICA TERRITORIAL. Orden de 12 de enero de 2015, de la Consejera de Medio Ambiente y Política Territorial por la que se establecen los requisitos para la utilización de los áridos reciclados procedentes de la valorización de residuos de construcción y demolición. Vitória. 2015.

DEPARTMENT OF PLANNING, TRANSPORT AND INFRASTRUCTURE OF SOUTH AUSTRALIA. Standard specification for supply and delivery of pavement materials. Adelaide, 2001.

DEUTSCHES INSTITUT FUR NORMUNG. DIN 4226-100 E: aggregates for concrete and mortar: part 100: recycled aggregates. Berlin, 2002.

DEVELOPMENT BUREAU OF THE GOVERNMENT OF THE HONG KONG. WBTC - Works Bureau Technical Circular No. 12/2002: specifications facilitating the use of recycled aggregates. Hong Kong, 2002.

EUROPEAN STANDARD. NBN EN 933-9: tests for geometrical properties of aggregates: part 9: assessment of fines: methylene blue test. Brussels, 2009.

FLORIDA DEPARTMENT OF TRANSPORTATION. Standard specifications for construction of roads and bridges. Flórida, 2017.

GONÇALVES, P.; BRITO, J. Recycled aggregate concrete (RAC): comparative analysis of existing specifications. Magazine of Concrete Research, v. 62, n. 5, p. 339-346, 2010

GRÊMIO DE ENTIDADES DEL RECICLAJE DE DERRIBOS. Asistencia técnica para el estúdio sobre la utilización de áridos sobre la utilización de áridos reciclados en la construcción de carreteras. Informe 3: La utilización de áridos reciclados en la construcción de carreteras, em Alemania, Países Bajos, Austria y Suiza. Madrid, 2005.

GRÊMIO DE ENTIDADES DEL RECICLAJE DE DERRIBOS. Guía Española de Áridos Reciclados Procedentes de Residuos de Construcción y Demolición. Madrid, 2012.

HANSEN, T. C. Recycled aggregates and recycled aggregate concrete second state-of-the-art report developments 1945-1985. Materials and Structures, v. 19, p. 201-246, 1986.

HENDRIKS, C. F.; JANSSEN, G. M. T.; VÁZQUEZ, E. Report 30: use of recycled materials - final report of RILEM Technical Committee 198-URM. Rilem Publications. p. 1-26, 2005

INSTITUTE OF PUBLIC WORKS ENGINEERING AUSTRALIA. Specification for supply of recycled material for pavements, earthworks and drainage. Sydney South, 2010.

JAPANESE INDUSTRIAL STANDARD. JIS A 50 21: recycled aggregate for concrete-Class H. Tokyo, 2005.

JAPANESE INDUSTRIAL STANDARD. JIS A 50 2122: recycled aggregate for concrete-Class M. Tokyo, 2007.

318 Alberte, E. P. V.; Handro, J. B. 
JAPANESE INDUSTRIAL STANDARD. JIS A 50 2123: recycled aggregate for concrete-Class L. Tokyo, 2006.

LEVY, S. M. Evolução histórica da utilização do concreto como material de construção. Boletim Técnico da Escola Politécnica da Universidade de São Paulo. São Paulo: Epusp, 2002.

MCNEIL, K.; KANG, T. H. Recycled concrete aggregates: a review. International Journal of Concrete Structures and Materials, v. 7, n. 1, p. 61-69, 2013.

MELO, A. V. S. Diretrizes para a produção de agregado reciclado em usinas de reciclagem de resíduos da construção civil. Salvador, 2011. Tese (Mestrado em Engenharia Ambiental Urbano) - Escola Politécnica, Universidade Federal da Bahia, Salvador, 2011.

MICHIGAN DEPARTMENT OF TRANSPORTATION. Standard specifications for construction. Michigan, 2012.

MINISTERIO DE FOMENTO. EHE-08: instrucción de hormigón estructural. Madrid, 2008.

NUNES, K. R. Avaliação de investimentos e desempenho de centrais de reciclagem para resíduos sólidos de construção e demolição. Rio de Janeiro: IBAM, 2004.

ORGANISME IMPARTIAL DE CONTRÔLE DE PRODUITS POUR LA CONSTRUCTION.

Prescriptions Techniques PTV 406 : granulats de debris de demolition et de construction recycle. Bruxeles, 2016.

PELLEGRINO, C.; FALESCHINI, F. Sustainability improvements in the concrete industry. Switzerland: Springer International, 2016.

PREFEITURA MUNICIPAL DE SÃO PAULO. Decreto $\mathbf{n}^{\circ} \mathbf{4 8 . 0 7 5}$, de 28 de dezembro de 2006. Dispõe sobre a obrigatoriedade da utilização de agregados reciclados, oriundos de resíduos sólidos da construção civil, em obras e serviços de pavimentação das vias públicas do município de São Paulo. São Paulo, 2006.

PREFEITURA MUNICIPAL DE SÃO PAULO. PMSP/SP ETS - 001/2003. Camadas de reforço do subleito, sub-base e base mista de pavimento com agregado reciclado de resíduos sólidos da construção civil. São Paulo, 2003.

RATCLIFFE, $S$. The use of crushed recycled concrete as an alternative concrete aggregate. Darwin, 2016. Thesis (Bachelor of Engineering) - Faculty of Engineering, Health, Science and the Environment, Charles Darwin University, Darwin, 2016.

RILEM. TC 121-DRG: specifications for concrete with recycled aggregates. Material and Structures, v. 27, n, 173, p. 557-559, 1994.

ROAD AND TRANSPORTATION RESEARCH ASSOCIATION. TL GESTEIN-STB: technical delivery terms for aggregates in road construction. Germany, 2004.

ROYAL NETHERLANDS STANDARDIZATION INSTITUTE. NEN 5905: dutch supplement to NEN-EN 12620 "Aggregates for concrete". Delft, 2005.

SOCIEDAD PÚBLICA DE GESTIÓN AMBIENTAL DEL GOBIERNO VASCO. Usos de áridos reciclados procedentes de Residuos de Construcción y Demolición: investigación prenormativa. País Basco, 2011.

SWISS ASSOCIATION OF ROAD AND TRANSPORTATION EXPERTS. SN 670 062: recyclage: généralités. Zurich, 1998a.

SWISS ASSOCIATION OF ROAD AND TRANSPORTATION EXPERTS. SN 670 142: recyclage: matériaux bitumineux de démolition. Zurich, 1998b.

SWISS ASSOCIATION OF ROAD AND TRANSPORTATION EXPERTS. SN 670 143: recyclage: béton de démolition. Zurich, 1998c.

SWISS ASSOCIATION OF ROAD AND TRANSPORTATION EXPERTS. SN 670 144: recyclage: matériaux de démolition non triés. Zurich, 1998d.

TAM, V. W. Y.; SOOMRO, M.; EVANGELISTA, A. C. J. A review of recycled aggregate in concrete applications (2000-2017). Construction and Building Materials, v. 172, p. 272-292, 2018.

TEXAS DEPARTMENT OF TRANSPORTATION. Specification 421: concret with hydraulic ciment. Texas, 2014. 
VÁZQUEZ, E. Recycled aggregates for concrete: problems and possible solutions. International Journal of Earth \& Environmental Sciences, v. 1, p. 1-5, 2016.

VYNCKE, J.; VRIJDERS, J. Recycling of C\&D waste in Belgium: state-of-the-art and opportunities for technology transfer. In: INTERNATIONAL CONFERENCE ON SUSTAINABLE CONSTRUCTION MATERIALS AND TECHNOLOGIES, 2., Ancona, 2010. Proceedings [...] Ancona, 2010.

XIAO, J. Recycled aggregate concrete structures. Berlin: Springer, 2018.

Elaine Pinto Varela Alberte

Departamento de Construção e Estruturas | Universidade Federal da Bahia | Rua Prof. Aristides Novis, $2,5^{\circ}$ andar, sala 02 , Federação | Salvador - BA - Brasil | CEP 40210-630 | Tel.: (71) 3283-9725 | E-mail: elaine.varela@ufba.br

Julia Barretto Handro

Departamento de Construção e Estruturas | Universidade Federal da Bahia | Rua Catharina Paraguassu, 112, Graça | Salvador BA - Brasil | CEP 40150-200 | Tel.: (71) 98125-2882 | E-mail: julia.handro@gmail.com

\section{Ambiente Construído}

Revista da Associação Nacional de Tecnologia do Ambiente Construído Av. Osvaldo Aranha, $99-3^{\circ}$ andar, Centro

Porto Alegre - RS - Brasil CEP $90035-190$

Telefone: +55 (51) 3308-4084

www.seer.ufrgs.br/ambienteconstruido www.scielo.br/ac

E-mail: ambienteconstruido@ufrgs.br 